\title{
A Meta-Analysis of Controlled Research on Social Skills Training for Schizophrenia
}

\author{
Matthew M. Kurtz \\ Wesleyan University
}

\author{
Kim T. Mueser \\ Dartmouth School of Medicine
}

\begin{abstract}
A meta-analysis of randomized, controlled trials of social skills training for schizophrenia was conducted. Outcome measures from 22 studies including 1,521 clients were categorized according to a proximaldistal continuum in relation to the presumed site of action of skills training interventions, with content mastery tests and performance-based measures of skills assumed to be most proximal, community functioning and negative symptoms intermediate, and general symptoms and relapse most distal. Results reveal a large weighted mean effect size for content-mastery exams $(d=1.20)$, a moderate mean effect size for performance-based measures of social and daily living skills $(d=0.52)$, moderate mean effect sizes for community functioning $(d=0.52)$ and negative symptoms $(d=0.40)$, and small mean effect sizes for other symptoms $(d=0.15)$ and relapse $(d=0.23)$. These results support the efficacy of social skills training for improving psychosocial functioning in schizophrenia.
\end{abstract}

Keywords: schizophrenia, social skills, meta-analysis

Poor psychosocial functioning is one of the defining characteristics of schizophrenia (American Psychiatric Association, 1994). A wealth of evidence shows that impaired social skills in occupational, social, and recreational situations are strongly related to worse psychosocial adjustment in clients with schizophrenia (Bellack, Morrison, Wixted, \& Mueser, 1990; Mueser \& Bellack, 1998). Furthermore, impairments in social skill often predate the onset of schizophrenia (Hans, Auerbach, Asarnow, Styr, \& Marcus, 2000), are present at the first episode (Addington, Saeddi, \& Addington, 2006), are stable over time in the absence of psychosocial treatment (Mueser, Bellack, Douglas, \& Morrison, 1991), and persist into senescence (Patterson, Goldman, McKibben, Davidson, \& Jeste, 2001).

Over the past 35 years, a variety of social skills training (SST) approaches have been developed to address impairments in social skills. Although skills training programs vary widely in content, duration, and the setting where they are implemented, they share a common set of strategies for teaching new skills based on social

Matthew M. Kurtz, Department of Psychology, Wesleyan University; Kim T. Mueser, Departments of Psychiatry and Community and Family Medicine, Dartmouth School of Medicine.

This work was supported in part by National Institute of Mental Health (NIMH) Grant K08 MH-69888 and a National Alliance for Research in Schizophrenia and Depression Young Investigator Award (awarded to Matthew M. Kurtz); as well as by NIMH Grants R34 MH-074786, R34 MH-0712529, R01 MH-77210, and R01 MH-064662; Substance Abuse and Mental Health Services Administration Grant SM-57261; and National Institute of Disability and Rehabilitation Research Grant H-133G050230 (awarded to Kim T. Mueser). We thank Robert P. Liberman for his thoughtful comments on a draft of this article as well as for making raw data from his studies available for this analysis, and Paul J. Moberg and Blair T. Johnson for consultation on technical aspects of the meta-analysis.

Correspondence concerning this article should be addressed to Matthew M. Kurtz, Department of Psychology, Judd Hall, Wesleyan University, Middletown, CT 06459. E-mail: mkurtz@wesleyan.edu learning theory (Bandura, 1969), including goal setting, role modeling, behavioral rehearsal, positive reinforcement, corrective feedback, and homework assignments to help promote generalization to the community. Several narrative reviews of research on SST for schizophrenia have been recently published (e.g., Bellack, 2004; Kopelowicz, Liberman, \& Zarate, 2006) but they have not included quantitative meta-analyses of the literature permitting direct comparisons of results across studies.

Two comprehensive meta-analyses of the SST literature in schizophrenia (Benton \& Schroeder, 1990) and severe mental illness (Dilk \& Bond, 1996) were published over 10 years ago Results of Benton and Schroeder's (1990) meta-analysis were relatively optimistic, with the authors concluding that effects of SST were large for specific behavioral measures of social skill and for self-reported social anxiety and assertiveness but smaller for measures of community functioning and symptoms. Similarly, Dilk and Bond (1996) reported large effect size changes for behavioral outcomes directly related to the focus of the SST interventions, such as assertiveness and interpersonal skill, but much smaller effects for improved instrumental role functioning or independent living. However, the authors also identified several significant limitations in research on SST extant at that time, noting that the majority of studies had been conducted in inpatient settings, with largely White, male populations and with training that tended to be brief in duration with limited follow-up.

Two more recent meta-analysis including only randomized controlled-studies have provided conflicting findings regarding the effectiveness of SST. In one meta-analysis, with only nine studies, Pilling et al. (2002) reported even less sanguine findings, concluding that when only randomized, controlled trials (RCTs) of SST were included there was little evidence of benefit on any outcomes. The results of this meta-analysis have been challenged on the basis of the authors' methods for combining results from studies using very different types of outcome measures (i.e., social skills assessments and social functioning in the community) and overlooking 


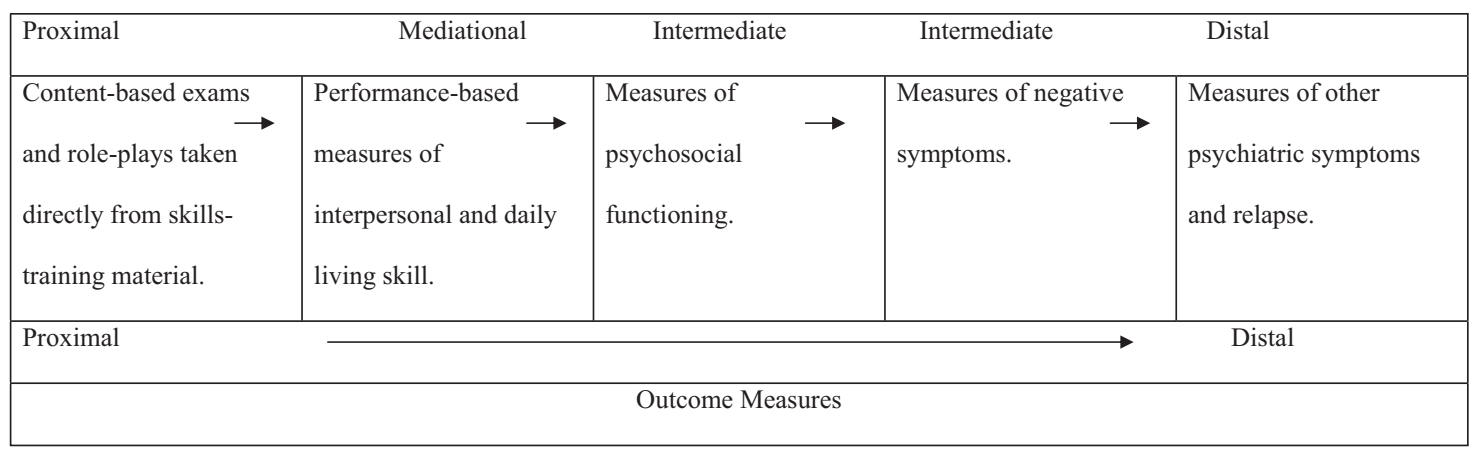

Figure 1. Organization of outcome measures for the meta-analysis reflecting proximity to the target of social-skills intervention. Larger effects on measures more proximal to the intervention are presumed.

salutary effects of SST that may have been obscured by active, therapeutic control conditions (see Mueser \& Penn, 2004). More recently, Pfammatter, Junghan, and Brenner (2006) investigated the effects of 19 RCTs of SST on measures skills acquisition, assertiveness, social functioning, and general psychopathology. Results from this analysis yielded large effects of SST on skills acquisition, with smaller, but significant, effects on assertiveness, social functioning, and general psychopathology. The conflicting conclusions of the meta-analyses of Benton and Schroeder (1990), Dilk and Bond (1996), Pilling et al. (2002), and Pfammatter et al. (2006), as well as additional RCTs conducted in recent years, suggest the time is ripe for a new meta-analysis of research on SST.

The goal of the current meta-analysis was to build on previous meta-analyses by (a) including only RCTs of SST; (b) including only studies with samples in which the majority of clients had diagnoses of schizophrenia or schizoaffective disorder; (c) investigating the impact of training variables (i.e., duration of SST program), experimental design issues (i.e., active vs. treatment-asusual [TAU] control conditions), and participant characteristics on observed outcomes; and (d) categorizing and evaluating outcome measures on a continuum of hypothesized proximal versus distal effects of SST, as illustrated in Figure 1. Specifically, on the basis of the theory of how SST works (Liberman et al., 1986), we expected that the impact of SST would be strongest on measures of content mastery of skills targeted by SST, followed by capacitybased measures of social and everyday life skills (e.g., role play tests), followed by measures of psychosocial functioning (e.g., social relationships, community adjustment) and negative symptoms. According to the stress-vulnerability model (Liberman et al., 1986; Zubin \& Spring, 1977), coping skills (including social skills) and social support are hypothesized to reduce the effects of stress on exacerbating psychotic symptoms; thus, SST was expected to have the smallest effect on the most distal outcomes of other (nonnegative) symptoms and relapse. We anticipated that the impact of SST on negative symptoms would fall between its effects on psychosocial functioning and other symptoms because measures of negative symptoms typically include some, but not all, items related to social adjustment. For example, the Scale for the Assessment of Negative Symptoms (Andreasen, 1984) and the Positive and Negative Syndrome Scale (Kay, Opler, \& Fiszbein, 1987) both contain items related to flattening of affect (i.e., not psychosocial functioning), whereas the Scale for the Assessment of Negative Symptoms also includes items related to social anhedonia, inpersistence at work or school, and poor personal hygiene, and the Positive and Negative Syndrome Scale also contains items related to active and passive social withdrawal.

\section{Method}

\section{Search Strategy}

Articles included in the meta-analysis were identified through a computer-based PsycINFO (American Psychological Association, 2000) search conducted from the beginning of this database (1887) to 2007. We conducted the search using the following keywords: severe mental illness, schizophrenia, social skills training, skills training, and workplace skills training. We completed a parallel search using the same keywords with the MEDLINE (National Library of Medicine, 1994) database from 1966 to 2007. The reference sections of articles located from both searches were studied for relevant citations.

\section{Inclusion Criteria}

Consistent with previous meta-analyses in this research area (e.g., Benton \& Schroeder, 1990), for an intervention to be defined as SST, it needed to include the following core behavioral techniques: instructions on the skill, live or taped modeling or role-play rehearsal, and positive and corrective feedback. Because a sufficient number of controlled studies of SST have been conducted at this point, in contrast to the earlier meta-analyses of SST (Benton \& Schroeder, 1990; Dilk \& Bond, 1996), we restricted our review to RCTs. Studies must have included a sample with at least a majority of clients with a diagnosis of schizophrenia or schizoaffective disorder. We excluded studies that included SST as one element of a broad array of interventions (e.g., Falloon et al., 2004; Thorup et al., 2005) because it was not possible to disentangle the effects of SST from other treatment components. We also excluded studies that (a) included family rather than client-focused approaches to SST (e.g., Kopelowicz, Zarate, Gonzalez Smith, Mintz, \& Liberman, 2003), (b) compared two forms of SST with one another (Glynn et al., 2002), or (c) represented pilot data from subsequently published studies (e.g., McQuaid et al., 2000) or clearly represented data duplicated from a published article already 
included in the meta-analysis (e.g., Lukoff, Wallace, Liberman, \& Burke, 1986; Wallace \& Liberman, 1985).

\section{Statistical Analysis}

Analyses were conducted according to procedures suggested by Rosenthal (1986) and Hedges and Olkin (1985). DSTAT Version 1.11 (Johnson, 1993) was used to calculate effect sizes and to carry out subsequent homogeneity and moderator variable analyses. The dependent measures were organized into five categories according to a proximal-distal continuum (see Figure 1): (1) measures of content mastery of skills training modules (proximal), (2) performance-based measures of social or functional skills capacity thought to mediate functional outcomes (proximal mediational), (3) measures of psychosocial functioning (intermediate), (4) negative symptoms (intermediate), and (5) measures of other symptoms and relapse (distal).

The unit of analysis in a meta-analysis is the effect size $(d)$. For purposes of the present study, the $d$ score was defined as the difference between intervention type (i.e., treatment vs. control) at termination of training, or the difference between intervention type (i.e., treatment vs. control) in pre-post training change within each study or comparison, expressed in standard deviation units. We converted study statistics to $d$ using formulas provided by Glass (1977). We used the pooled standard deviation using the formula of Rosenthal (1994). Because of the potential for inflated withingroup effects relative to between-groups comparisons (Lipsey \& Wilson, 1993), we did not compare within-group pre- to posttreatment change. Instead, effect sizes comparing experimental to control conditions were calculated for each study for either posttraining scores or for differences between groups in change from pre- to posttesting $\left(M_{\text {post or change exp }}-M_{\text {post or change control }} /\right.$

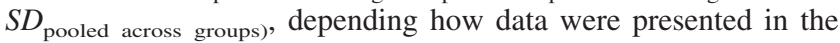
study. Potential bias is introduced with the computation of effect sizes from between-groups differences in pre-post testing change, as change scores typically have lower variance than pre- or posttraining scores alone, thus possibly exaggerating the observed effect size for these studies. To ensure that the combination of effect sizes computed from cross-sectional posttraining and prepost training change scores did not bias results of our metaanalysis, for each outcome domain we calculated the mean $d$ for all studies and then the mean $d$ for only "unbiased" cross-sectional studies to address any possible systematic bias. One identified study (Chien et al., 2003) did not present data from measures that fit into one of the five domains of outcome selected for this study and, thus, was excluded from the analysis. For studies with multiple measures in the same outcome domain, we selected the measure within that domain with the smallest effect size. Nonsignificant results lacking supporting statistical information were coded as an effect size of zero (Glass, McGaw, \& Smith, 1981). By expressing effect size in standard deviation units, we were able to make a direct comparison of outcomes across studies. Effects were categorized as small $(0.2)$, medium $(0.5)$ or large ( 0.8 or greater; Cohen, 1977).

Each analysis was conducted in several steps. First, we derived Hedges's $g$ for each study using raw means and standard deviations, as well as $t, F$, or $p$ statistics reported in the individual study (Hedges \& Olkin, 1985; Rosenthal, 1994). Although Hedges's $g$ is an estimate of effect size, the $g$ statistic is known to overestimate the population effect size when sample sizes are small (Rosenthal, 1994). To correct for this bias, we subsequently transformed Hedges's $g$ into an unbiased measure of effect size, Cohen's $d$ (Hedges, 1981; Hedges \& Olkin, 1985). We thereafter combined individual values of $d$ across studies and weighted them according to their variance using a fixedeffects model. We analyzed potential differences in effect size between studies using the method of Hedges and Olkin (1985). This procedure computes mean weighted effect sizes and $95 \%$ confidence intervals (CIs) for each variable subset and allows for the testing of the influence of each individual factor on the overall results using the $Q$ statistic. The test for heterogeneity $Q_{\mathrm{T}}$ is based on the sum of squares of the individual effect sizes around the mean when each square is weighted by the inverse of the estimated variance of the effect size. $Q$ has an asymptotic chi-square distribution and is analogous to the analysis of variance. Studies were evaluated for within-group differences $\left(Q_{\mathrm{W}}\right)$ and between-groups differences $\left(Q_{\mathrm{B}}\right)$ following the same model.

To address the "file-drawer" or publication bias problem in meta-analytic investigations in which null results from a study are presumed to be less likely published than results showing expected differences between treatment groups, we calculated a fail-safe $N$ for each class of outcome variable by the method of Orwin (1983). This measure provides an estimate of the number of studies with null results that would be needed to reduce the obtained mean effect size to a nonsignificant level. In the absence of a universally accepted significance level for effect sizes, an effect size of .20 was considered nonsignificant (Orwin, 1983).

\section{Moderator Variable Analysis}

Sample characteristics of mean age, mean duration of illness, in versus outpatient status, and treatment and design characteristics of duration of social-skills treatment in both weeks and hours, treatment intensity (hours per week), and active versus TAU controls were selected as moderator variables. Although we only included studies in this meta-analysis of the highest design quality (RCTs), even within this carefully selected group, distinctions in design quality could be made. We differentiated design quality of selected studies on the basis of ratings of three elements that related to the validity of each study: (1) use of raters blind to the condition of the participants, (2) establishment of interrater reliability on outcome measures, and (3) formal measures of treatment fidelity. Each study received a score of " 1 " (included none of these aspects of design quality), "2" (included one of these measures of design quality), "3" (included two of these measures of design quality), or "4" (included all three of these aspects of design quality).

Continuous data (i.e., age, duration of illness, weeks and hours of SST, and intensity) were analyzed with a continuous model (Rosenthal, 1986) with a $Z$ test for significance of model fit. Group comparisons were made for categorical moderator variables (e.g., inpatient vs. outpatient). In these comparisons, analysis of variance type summary values were estimated for the group effect. Analyses were only applied to those outcome domains represented in at least five RCTs. Significance tests for these analyses were two-tailed, and $p$ was set at .05 . 
Results

\section{Study Characteristics}

As can be seen in Table 1, a total of 23 randomized, controlled studies were identified including 1,599 clients, with a range of sample sizes from 16 to 240 participants $(M=69.5$ participants, $S D=46.2$ ). For studies that reported sex of participants, $71 \%$ of all participants were male. A majority of the studies were conducted with outpatients (63\%), and with the exception of three studies, consisted of older clients who had been ill for a mean duration of 16.7 years ( $S D=6.2 ; 11$ studies). For the 19 studies that reported mean age, age across study samples was 37.7 years $(S D=6.9)$, whereas mean education from the eight studies that reported these data was 12.5 years $(S D=0.8)$. The majority of studies included exclusively schizophrenia-schizoaffective disorder samples (87\%). Only five studies (23\%) included clients with diagnoses confirmed by structured clinical interviews, and only nine studies (39\%) reported a formal mechanism for ascertaining treatment fidelity. Eleven studies (48\%) explicitly used ratings of outcomes by staff blind to the clients' treatment condition. Duration of treatment ranged widely from a minimum of $8 \mathrm{hr}$ to a maximum of $312 \mathrm{hr}$ of training $(M=67.2 \mathrm{hr}, S D=75.4)$ occurring over $2-104$ weeks ( $M=19.3$ weeks, $S D=22.7)$.

In terms of interventions, eight studies (33\%) focused primarily on social interaction skills, with some of these studies including an explicit social perception training component (e.g., Hogarty et al., 1986, 1991). Five studies (23\%) focused on medication and/or illness self-management skills, four studies (18\%) focused on training for community reentry following a hospitalization for acute symptoms, three studies (13\%) focused on workplace social skills, two studies (9\%) focused primarily on learning functional activities-of-daily-living, and one study (4\%) integrated explicit cognitive-behavioral strategies in an attempt to enhance behavioral acquisition of social skills. Control conditions in most studies (76\%) included active interventions, with the remainder using TAU as a control condition.

\section{Effects of SST on Proximal Measures of Content Mastery}

The results of the meta-analysis are presented in Table 2. Of the 23 RCTs identified, 7 provided data on assessments of content mastery of skills taught in the various SST interventions. These measures typically included paper-and-pencil or interview-based measures of knowledge acquisition, and in one case (Kopelowicz, Wallace, \& Zarate, 1998) structured role plays closely linked to the relevant training program. The weighted mean effect size was very large (1.20), with a 95\% CI of 0.96-1.43. As this CI does not include zero it can be considered to be significant, and the lack of heterogeneity suggests that the group of studies share a common effect size. The fail-safe $N$ showing that 5 times the number of identified studies in the literature, all reporting negative results, would be necessary to reduce this finding to a null effect indicates it is highly stable.

\section{Effect of SST on Performance-Based Measures of Social and Daily Living Skills}

Seven studies provided data on performance-based social and daily living skills, usually collected through the use of role-play tests of simulated social interactions. Four studies focused solely on social skills, whereas one included performance-based measures of activities of daily living only. The other two studies included a combination of these measures. The weighted mean effect size was moderate and significant $(d=0.52 ; 95 \% \mathrm{CI}=$ $0.34,0.71)$. There was also significant heterogeneity in overall effect sizes between studies, suggesting that these studies did not share a common effect. Analysis of client characteristics indicated that SST had stronger effects on younger samples $(Z=-3.78, p<$ .0005). Inpatient (compared with outpatient) sample studies had a larger weighted mean effect size at a trend level $\left(d_{1}=0.82\right.$ vs. $\left.d_{2}=0.42 ; Q_{\mathrm{B}}[1]=3.5, p<.06\right)$. From a design perspective, those studies that compared SST to a TAU control had significantly larger effects than those comparing SST to an active control condition $\left(d_{1}=0.87\right.$ vs. $\left.d_{2}=0.09 ; Q_{\mathrm{B}}[1]=16.4, p<.0005\right)$, and from a treatment perspective, paradoxically, SST programs with a shorter duration in weeks and of less intensity produced a greater weighted mean effect size than longer duration programs of greater intensity $(Z=-4.31, p<.0001 ;$ and $Z=-2.92, p<.005$, respectively).

\section{Effect of SST on Measures of Community and Institutional Functioning}

Seven studies provided measures of community or institutional functioning. Results revealed a moderate and significant mean effect size $(d=0.52 ; 95 \% \mathrm{CI}=0.31,0.73)$ of SST that was stable across studies.

\section{Effect of SST on Psychiatric Symptoms and Relapse}

Six studies investigated negative symptoms directly. Results of these studies revealed a moderate mean weighted effect size $(d=$ $0.40 ; 95 \% \mathrm{CI}=0.19,0.61)$ that was unstable. Moderator variable analysis revealed that a younger age predicted a larger effect size improvement in negative symptoms at a trend level $(Z=-1.85$, $p<.065)$. Studies of greater design quality showed smaller effects than those of worse quality $\left(d_{1}=-0.07\right.$ vs. $d_{2}=0.65 ; Q_{\mathrm{B}}[1]=$ $10.2, p<.005)$.

Ten studies provided data on overall symptoms. The effect size for overall symptoms was small $(d=0.15)$, stable, and nonsignificant insofar as the $95 \% \mathrm{CI}$ included zero $(-0.01,0.31)$. Nine studies included measures of relapse, defined variously as either hospital readmission, an increase in psychotic symptoms, or a suicide attempt. Relapse was assessed during different time intervals in different studies. In three studies relapse was assessed a year after termination of treatment, in two studies it was assessed during a year of treatment, in one study it was assessed during the 6 months of treatment, in one study it was assessed 6 months after treatment, and in one study it was assessed during 4.5 months of treatment and 6 months of follow-up (in the last of the nine studies, the follow-up period was not defined). The mean weighted effect size was small, stable, and statistically significant $(d=0.23 ; 95 \%$ $\mathrm{CI}=0.04,0.41)$.

\section{Discussion}

The results of this meta-analysis were consistent with the hypothesis that the impact of SST is strongest on those outcome 
domains believed to be most proximal to the intervention and weakest on the most distal domains. In fact, the magnitude of the average effect sizes for the different outcome domains corresponded to our hypothesized ordering of those domains along a proximal-distal continuum (see Figure 1), with the effects strongest on content mastery of skills directly taught in SST $(d=1.20)$, followed by performance-based measures of social and independent living skill $(d=0.52)$, psychosocial functioning $(d=0.52)$, and then negative symptoms $(d=0.40)$. The effects of SST were weakest on the most distal outcome measures of relapse $(d=0.23)$ and other (nonnegative) symptoms $(d=0.15)$, with only the last outcome domain (other symptoms) not being statistically significant. This pattern of findings highlights the utility of categorizing the various targeted domains of a treatment on the basis of their proximity to the intervention's presumed mechanism of action (Brenner, Curbow, \& Legro, 1995) and organizing the analysis of those domains accordingly.

Although the primary rationale for SST in schizophrenia is to improve psychosocial functioning, despite decades of research there has continued to be debate about whether SST is effective at achieving this goal. Narrative reviews have tended to find support for the efficacy of SST (Bellack, 2004; Kopelowicz et al., 2006), but prior meta-analyses have questioned its impact on functioning (Benton \& Schroeder, 1990; Dilk \& Bond, 1996; Pilling et al., 2002). This has led to conflicting recommendations about the role of SST in the treatment of schizophrenia, with skills training endorsed by the Patient Outcomes Research Team in the United States (Lehman \& Steinwachs, 1998) but not by the National Institute for Clinical Excellence in Great Britain (National Collaborating Centre for Mental Health, 2003). Because of the growing body of research on SST, the present review was able to include more studies and therefore to shed light on this question. The average effect size of SST on psychosocial functioning was highly significant, in the moderate range, and consistent across studies. This result supports the utility of SST for improving functional outcomes, such as social adjustment and independent living. The inclusion of studies of only the highest design quality (RCTs), along with the computation of effect sizes for SST against active psychosocial control therapies in a majority of studies, highlights the robustness of these findings. Furthermore, SST also had a moderate average effect size on improving negative symptoms, which are strongly associated with impaired psychosocial functioning in schizophrenia (Mueser, Bellack, Morrison, \& Wixted, 1990; Sayers, Curran, \& Mueser, 1996). Taken together, these findings show strong evidence for the generalization of SST interventions from the training environment to the more complex spheres of everyday functioning.

It is of note that the magnitude of the mean effect size for performance-based measures of social skill (0.52) was identical to that of actual measures of community and institutional functioning (0.52), despite the hypothesis that social skill mediates psychosocial functioning and was thought to be more proximal to the effects of SST interventions, and thus expected to show larger effects. These findings are intriguing. One possible explanation is that SST may serve to behaviorally activate the use of social skills in appropriate situations in some clients who already have the skills in their repertoire but ordinarily fail to use them. The practical focus of SST on helping clients achieve personal goals through practicing effective behaviors, combined with abundant social reinforcement, may bolster the self-efficacy (Pratt, Mueser, Smith, $\& \mathrm{Lu}, 2005)$ and willingness to use existing skills in some clients. It is also possible that role-play tests are a direct indicator of psychosocial functioning, rather than just a measure of social skill. Role-play tests are strongly related to psychosocial functioning in schizophrenia (Bellack, Brown, \& Thomas-Lohrman, 2006; Bellack, Morrison, Mueser, Wade, \& Sayers, 1990). Lastly, role-play tests may be providing an indirect measure of motivation and effort, rather than social skill per se, and perhaps it is improvements in these functions that are mediating improved psychosocial functioning. More research is needed aimed at understanding how SST improves psychosocial functioning and the role of skill acquisition in contributing to functional gains.

Although SST had significant and moderate-sized effects on community or institutional functioning and negative symptoms, its effects were small on other psychiatric symptoms and relapsedomains presumed to be the most distal from the effects of the intervention. The limited effect of SST on relapses and symptom severity may reflect the multidetermined nature of these disease domains. Improved social skills are hypothesized to reduce symptoms and relapses through improved coping and social support (Liberman et al., 1986). However, numerous other factors are also know to affect symptoms and relapses - such as medication nonadherence (Chen et al., 2005), substance abuse (Drake \& Brunette, 1998), and emotionally charged family relationships (Butzlaff \& Hooley, 1998)—diluting the potential impact of improved social skills alone for reducing psychopathology and risk of relapse.

Moderator analyses indicated that that the observed effects of SST on negative symptoms were greatly reduced in studies of higher design quality and that study samples that included younger clients were more likely to show improvement in negative symptoms than older samples at a trend level. The effects of study design quality suggest that additional RCTs of SST utilizing blinded assessment, interrater reliability training for selected outcome measures, and formalized assessment of intervention fidelity are necessary to assess whether there are true effects of SST on negative symptoms. It is unclear whether the poorer response in negative symptoms for older clients reflects a characteristic of the sample or the degree to which SST programs fail to address the needs of older clients. If the latter, this finding would emphasize the importance of developing novel SST programs that address the needs and negative symptoms of older clients (Pratt, Van Critters, Mueser, \& Bartels, in press).

With respect to performance-based measures of social and everyday living skills, moderator variable analyses revealed that younger sample age, comparison to a nonactive control condition, inpatient status (at a trend level), and, paradoxically, shorter duration and intensity of training produced larger effects. It is possible that shorter interventions, by targeting a more restricted range of social skills, may have produced a more concentrated effect on measures of outcome closely linked to the intervention. It is of note that for studies included in this analysis, shorter treatment duration was associated with inpatient status, making it unclear whether illness acuity, duration of intervention, or an interaction of these factors influenced observed effect sizes. It is also possible that larger effects with shorter treatment durations could reflect an artifact of including two studies with highly atypical treatment duration (4 weeks of SST treatment). 


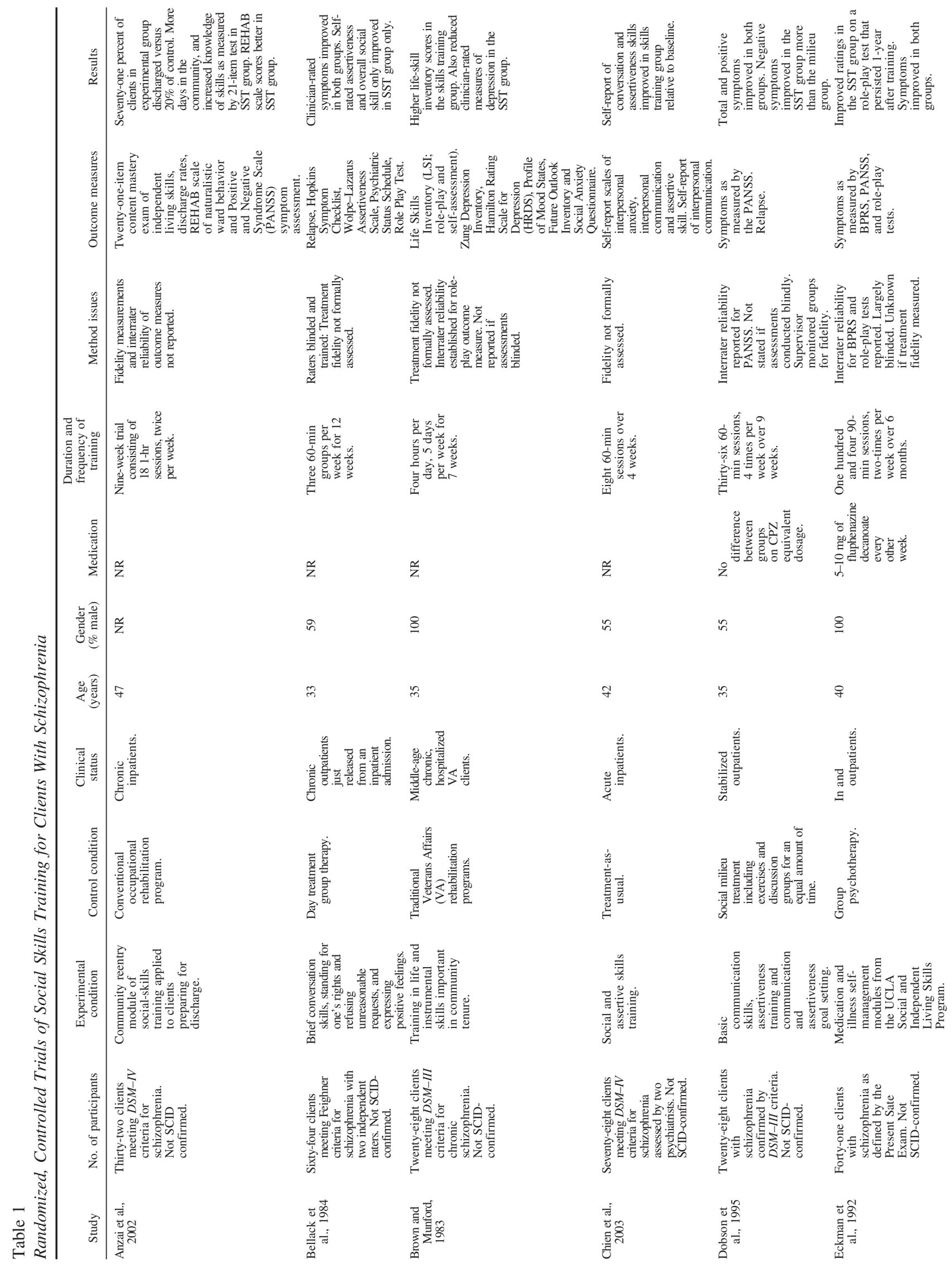




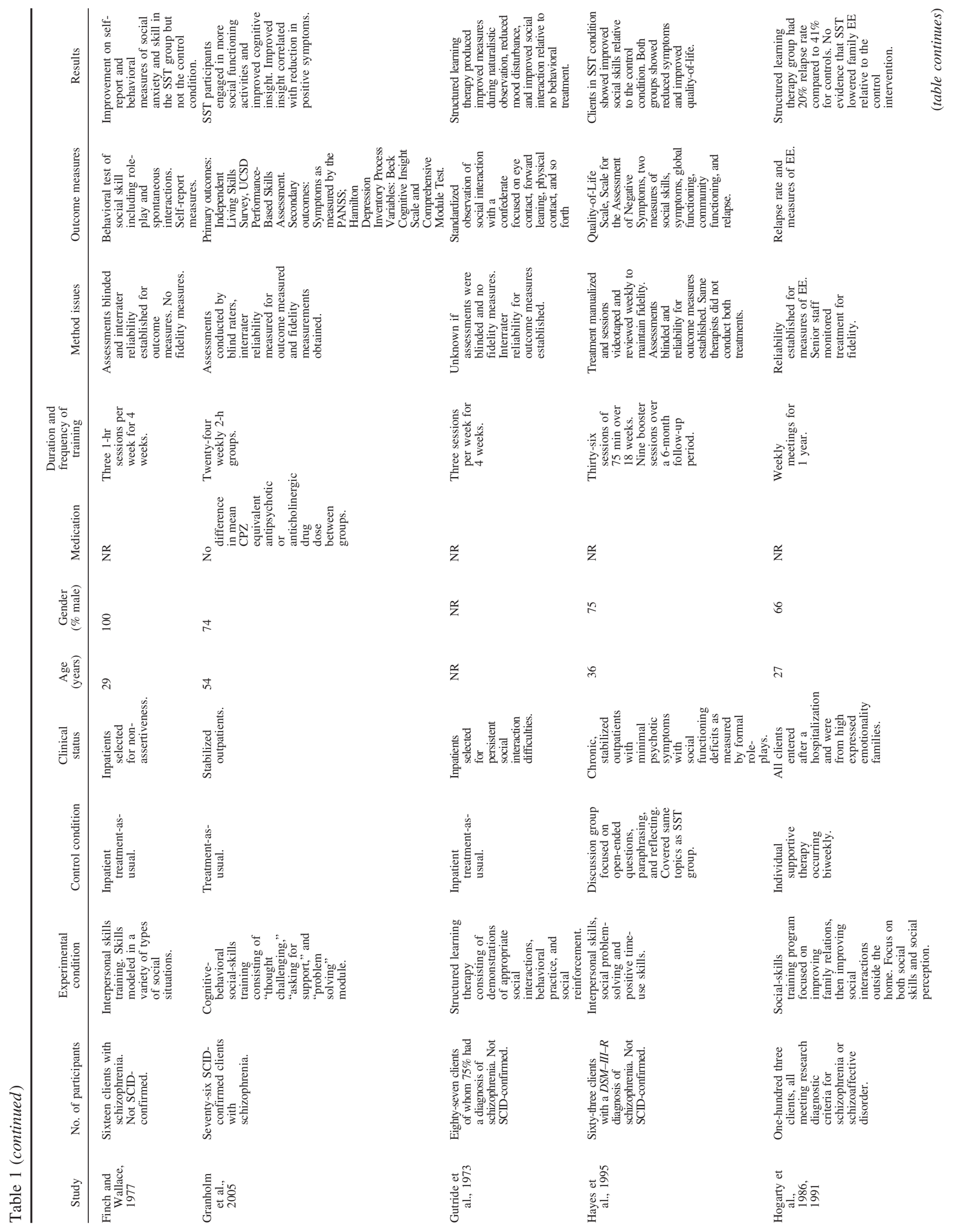




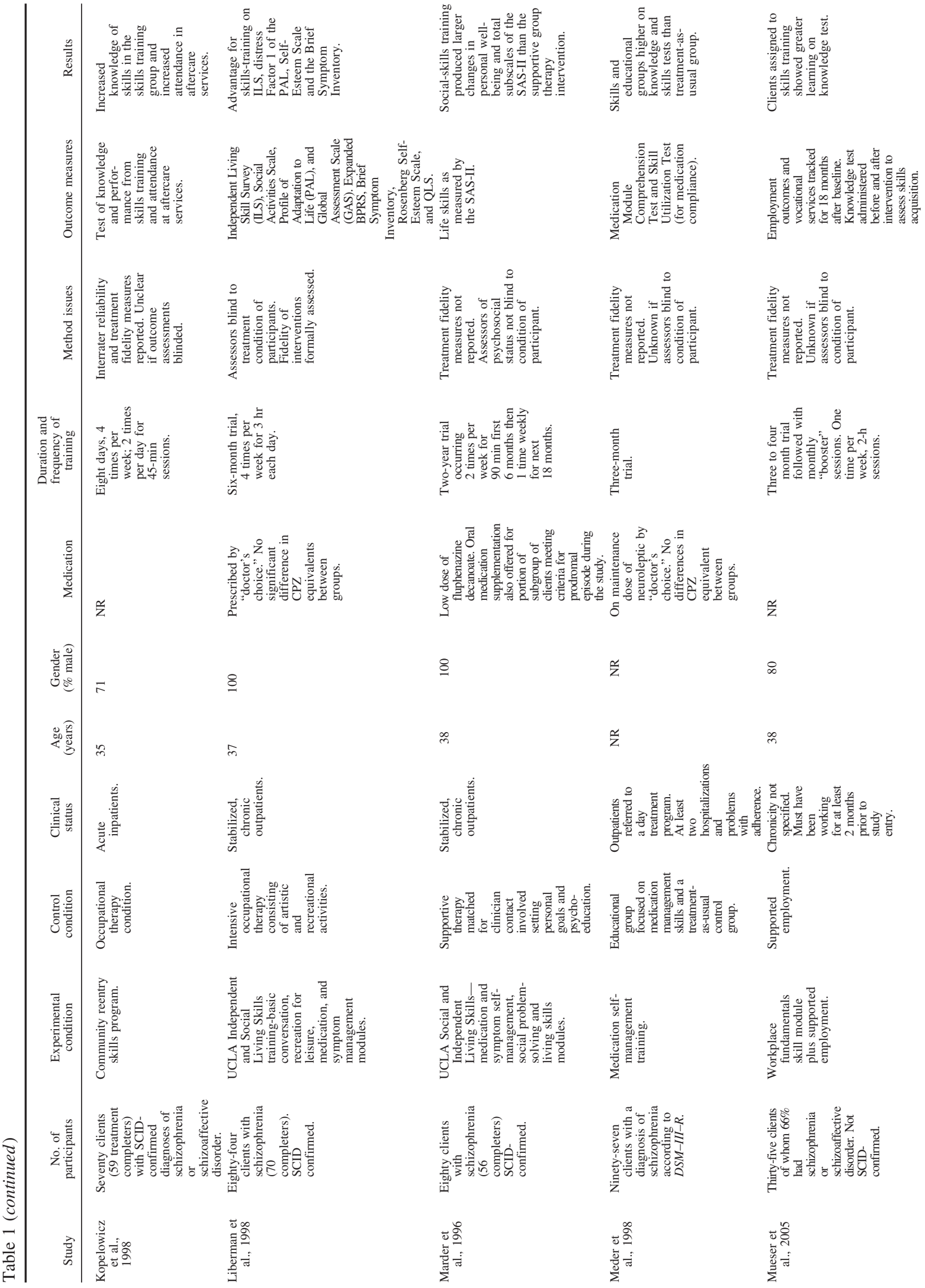




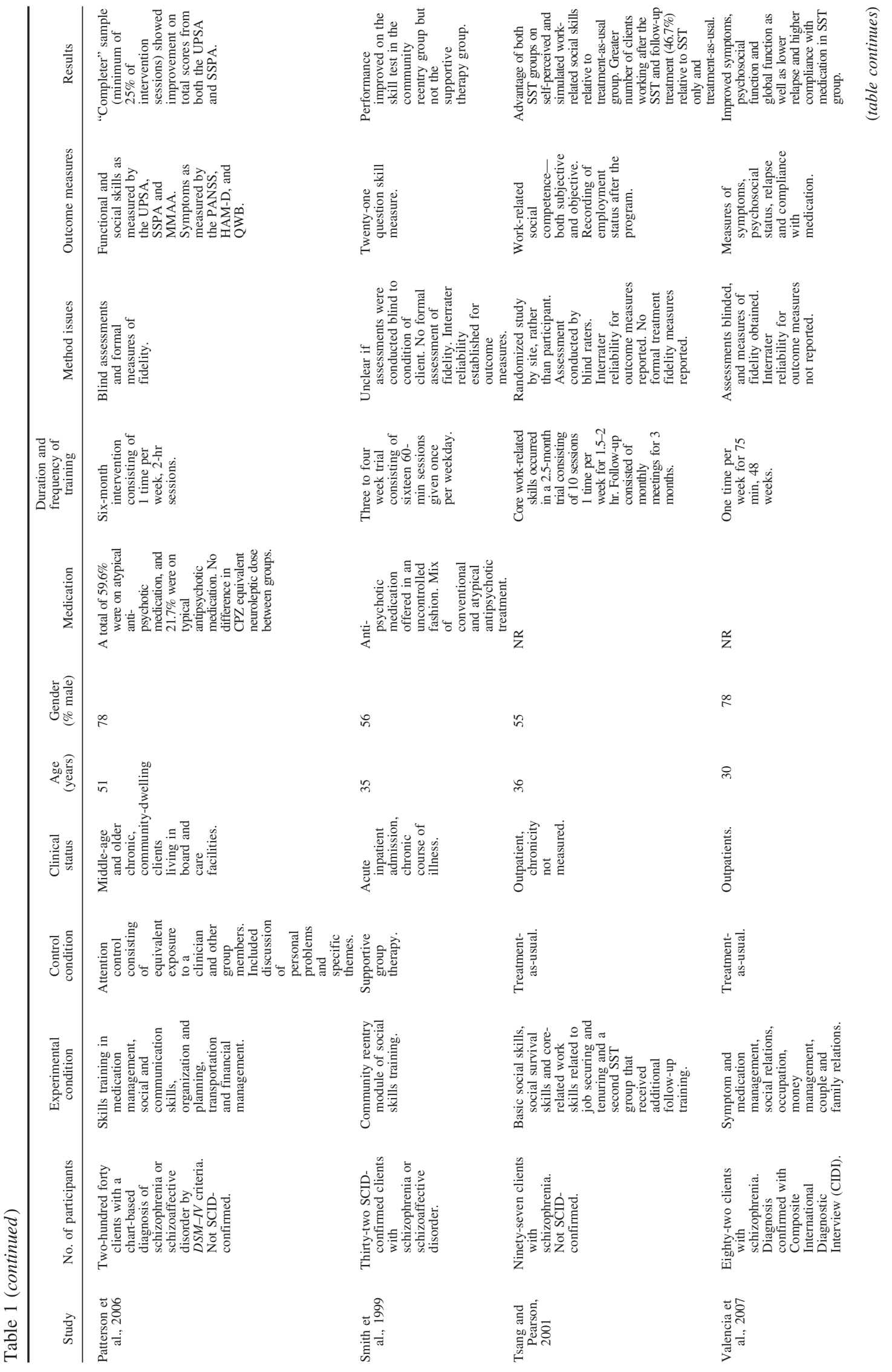




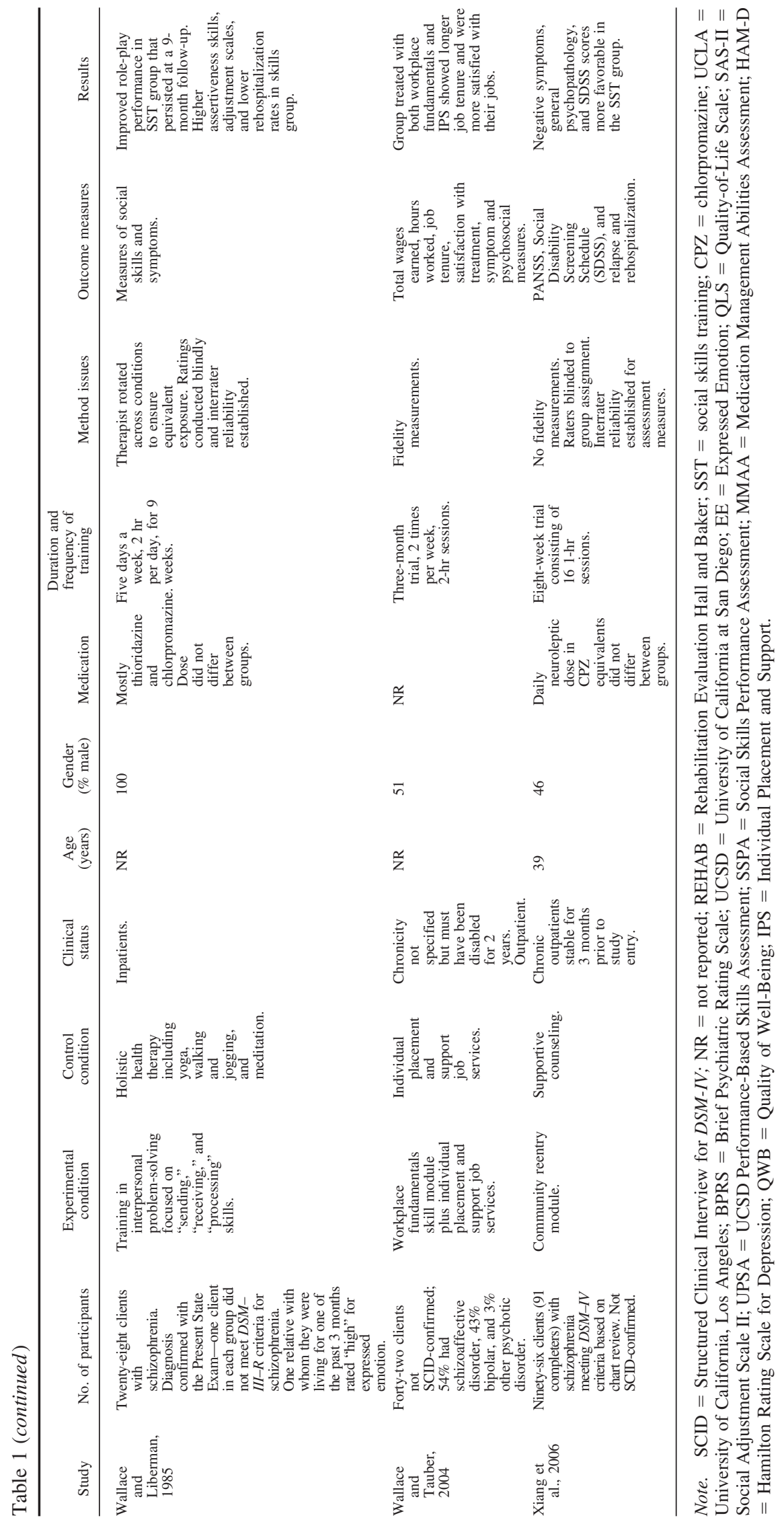


Table 2

Mean Effect Sizes for Randomized, Controlled Studies of Social-Skills Training for Clients With Schizophrenia Organized by Measured Area of Outcome and Proximity of the Outcome Area to the Presumed Effects of Intervention

\begin{tabular}{|c|c|c|c|c|c|c|c|c|}
\hline Outcome measures & Study type & $k$ & $N$ & ES & $95 \% \mathrm{CI}$ & $Z$ & $Q_{\mathrm{W}}$ & $N_{\mathrm{fs}}$ \\
\hline \multicolumn{9}{|l|}{ Proximal measures } \\
\hline \multirow[t]{2}{*}{ Content Mastery Exams } & All studies & 7 & 330 & 1.20 & $0.96,1.43$ & $9.98^{* * *}$ & 2.15 & 35 \\
\hline & Unbiased only & 6 & 254 & 1.16 & $0.89,1.43$ & $8.50^{* *}$ & 1.77 & 29 \\
\hline \multicolumn{9}{|l|}{ Proximal mediational measures } \\
\hline \multirow{2}{*}{$\begin{array}{l}\text { Performance-based measures of social } \\
\text { skill and daily living skills }\end{array}$} & All studies & 7 & 481 & 0.52 & $0.34,0.71$ & $5.50^{* *}$ & $35.87^{* *}$ & 11 \\
\hline & Unbiased only & 5 & 377 & 0.48 & $0.27,0.69$ & $4.50^{* *}$ & $31.48^{* * *}$ & 7 \\
\hline \multicolumn{9}{|l|}{ Intermediate measures } \\
\hline \multirow[t]{2}{*}{ Psychosocial functioning } & All studies & 7 & 371 & 0.52 & $0.31,0.73$ & $4.86^{* *}$ & 9.55 & 11 \\
\hline & Unbiased only & 4 & 230 & 0.41 & $0.15,0.68$ & $3.05^{* *}$ & 11.63 & 4 \\
\hline \multirow[t]{2}{*}{ Negative symptoms } & All studies & 6 & 363 & 0.40 & $0.19,0.61$ & $3.75^{* *}$ & $18.82^{*}$ & 6 \\
\hline & Unbiased only & 5 & 287 & 0.47 & $0.24,0.71$ & $3.90^{* *}$ & $17.26^{*}$ & 7 \\
\hline \multicolumn{9}{|l|}{ Distal measures } \\
\hline \multirow[t]{2}{*}{ Other psychiatric symptoms } & All studies & 10 & 604 & 0.15 & $-0.01,0.31$ & 1.85 & 11.71 & \\
\hline & Unbiased only & 7 & 411 & 0.20 & $0.00,0.39$ & 1.96 & 9.84 & \\
\hline Relapse/rehospitalization & $\begin{array}{l}\text { All studies } \\
\quad \text { (none biased) }\end{array}$ & 9 & 485 & 0.23 & $0.04,0.41$ & $2.45^{*}$ & 4.32 & 1 \\
\hline
\end{tabular}

Note. Unbiased effect sizes (ESs) represent only those calculated from between-groups, posttreatment study results. $k=$ number of studies; $N=$ number of clients; $95 \% \mathrm{CI}=95 \%$ confidence interval; $Z=$ significance test within the group; $Q_{\mathrm{W}}=$ homogeneity statistic; $N_{\mathrm{fs}}=$ indicates the number of null findings that would need to be found to reduce the mean effect size to 20 .

${ }^{*} p<.05$. ${ }^{* * *} p<.01$.

The importance of these moderator variable findings is unclear, however, in light of the lack of moderator effects on the more critical outcome of psychosocial functioning. For example, the findings indicated that younger, more acute clients show a greater response to SST on performance tests of skills and daily living capacity. If performance-based measures of social skill are actually more sensitive indicators of psychosocial functioning than currently available measures of such functioning, these findings could point to the need to tailor new SST interventions to the characteristics of those clients who improve the least from SST (e.g., older clients). On the other hand, if measures of psychosocial functioning are more valid indicators of this domain than performancebased tests, these moderator effects may be of more theoretical than clinical significance.

It is important to note that our meta-analysis included effect sizes computed from both raw, between-groups posttraining scores, and between-groups pre- to posttraining change scores. Effect sizes computed from change scores may exaggerate observed effects, as the variance associated with these scores is typically less than the raw scores from which they are derived. Removal of effect sizes that were potentially biased in this manner, however, had little effect on the mean $d$ value for each outcome domain (see Table 2).

Several caveats to the current findings should be noted. First, the overall sample of 22 RCTs of SST was small, and the number of studies with data for each of the outcome domains was even smaller. Thus, as the number of RCTs of skills training grows in the future, the findings of this meta-analysis will require replication. Second, the vast majority of studies included in this metaanalysis failed to report crucial sample information, such as age of illness onset (15 of 23) and dosage and/or type of medication (15 of 23), limiting the number of variables that could be investigated in this analysis and suggesting that some variables that may have had an impact on SST effects remain to be explored. Third, some of the moderator variable analyses included a very small numbers of studies (e.g., only three of the seven SST studies included clinic-based measures of functional capacity reported sample duration of illness), making the power to detect some relationships limited. Fourth, as is common to all meta-analyses, it is unknown the degree to which our findings may represent publication bias. Inclusion of unpublished negative findings would affect our overall results, and their absence may have led us to overestimate our reported effect sizes.

In summary, with respect to other meta-analyses of RCTs of SST, our findings are quite consistent with those of Pfammatter et al. (2006), who found large effects on skill measures more proximal to the locus of SST interventions, and smaller, but significant, effects on more distal measures of social functioning and general psychopathology. Our findings are discrepant from the largely negative results reported by Pilling et al. (2002). The larger number of studies included in the current analysis (22 vs. 9), coupled with Pilling et al.'s grouping of outcome measures that varied with respect to their proximity to the locus of SST treatments, most likely accounts for this difference.

The results of this meta-analysis suggest several avenues for future study. First, it remains unclear to what degree clients with later onset of illness and better premorbid skill will benefit from SST interventions aimed at helping them rehearse previously acquired skills as compared to clients with an earlier age of onset and for whom skills are acquired for the first time. Studies that stratify clients according to early versus late age of onset, or lower versus higher premorbid functioning, could address this question. Second, many of the studies in this meta-analysis include outcome measures from only one or two outcome domains. Including measures from a variety of outcome domains differing in their proximity to the locus of the SST intervention will provide greater clarity 
regarding the effects of this intervention. Third, there is evidence that neurocognitive deficits in attention, memory, and problem solving may be evident in as many as $70 \%$ of clients with schizophrenia (Palmer, Heaton, Kuck, \& Braff, 1997) and can affect the likelihood of benefit from SST interventions (Mueser, Bellack, Douglas, \& Wade, 1991). In recent years a variety of novel behavioral approaches for treatment of cognitive deficits in people with schizophrenia have been developed and manualized, and initial findings have been promising (for a review, see McGurk, Twamley, Sitzer, McHugo, \& Mueser, 2007). Thus, combined treatment of neurocognitive deficits and SST may be a fruitful avenue of future research for enhancing the effects of SST in this population. Last, the number of RCTs, including follow-up data after cessation of skills training, was too small to compute meaningful mean effect sizes. Given the time and effort-intensive nature of SST, understanding the durability of treatment effects and the potential necessity of booster sessions will be crucial in maximizing its benefit.

\section{References}

*References marked with an asterisk indicate studies included in the meta-analysis.

Addington, J., Saeddi, H., \& Addington, D. (2006). Influence of social perception and social knowledge functioning on cognitive and social functioning in early psychosis. British Journal of Psychiatry, 189, 373378.

American Psychiatric Association. (1980). Diagnostic and statistical manual of mental disorders (3rd ed.). Washington, DC: Author.

American Psychiatric Association. (1987). Diagnostic and statistical manual of mental disorders (3rd ed., rev.). Washington, DC: Author

American Psychiatric Association. (1994). Diagnostic and statistical manual of mental disorders (4th ed.). Washington, DC: Author.

American Psychological Association. (2000). PsycINFO database. Washington, DC: Author.

Andreasen, N. C. (1984). Modified Scale for the Assessment of Negative Symptoms. Bethesda, MD: U.S. Department of Health and Human Services.

*Anzai, N., Yoneda, S., Kumagai, N., Nakamura, Y., Ikebuchi, E., \& Liberman, R. P. (2002). Training persons with schizophrenia in illness self-management: A randomized controlled trial in Japan. Psychiatric Services, 53, 545-547.

Bandura, A. (1969). Principles of behavior modification. New York: Holt, Rinehart and Winston.

Bellack, A. S. (2004). Skills training for people with severe mental illness. Psychiatric Rehabilitation Journal, 27, 375-391.

Bellack, A. S., Brown, C. H., \& Thomas-Lohrman, S. (2006). Psychometric characteristics of role play assessments of social skill in schizophrenia. Behavior Therapy, 37, 339-352.

Bellack, A. S., Morrison, R. L., Mueser, K. T., Wade, J. H., \& Sayers, S. L. (1990). Role play for assessing the social competence of psychiatric patients. Psychological Assessment, 2, 248-255.

Bellack, A. S., Morrison, R. L., Wixted, J. T., \& Mueser, K. T. (1990). An analysis of social competence in schizophrenia. British Journal of Psychiatry, 156, 809-818.

*Bellack, A. S., Turner, S. M., Hersen, M., \& Luber, R. F. (1984). An examination of the efficacy of social skills training for chronic schizophrenia patients. Hospital and Community Psychiatry, 35, 1023-1028.

Benton, M. K., \& Schroeder, H. E. (1990). Social skills training with schizophrenics: A meta-analytic evaluation. Journal of Consulting and Clinical Psychology, 58, 741-747.

Brenner, M. H., Curbow, B., \& Legro, M. W. (1995). The proximal-distal continuum of multiple health outcome measures: The case of cataract surgery. Medical Care, 33(Suppl. 4), AS236-AS244.

*Brown, M. A., \& Munford, A. M. (1983). Life skills training for chronic schizophrenics. The Journal of Nervous and Mental Disease, 171, 466470.

Butzlaff, R. L., \& Hooley, J. M. (1998). Expressed emotion and psychiatric relapse. Archives of General Psychiatry, 55, 547-552.

Chen, E. Y. H., Hui, C. L. M., Dunn, E. L. W., Miao, M. Y. K., Yeung, W. S., Wong, C. K., et al. (2005). A prospective 3-year longitudinal study of cognitive predictors of relapse in first episode patients. Schizophrenia Research, 77, 99-104.

Chien, H. C., Ku, C. H., Lu, R. B., Chu, H., Tao, Y. H., \& Chou, K. R. (2003). Effects of social skills training on improving social skills of patients with schizophrenia. Archives of Psychiatric Nursing, 17, $228-$ 236.

Cohen, J. (1977). Statistical power analysis for the behavioral sciences. New York: Academic Press.

Dilk, M. N., \& Bond, G. R. (1996). Meta-analytic evaluation of skills training research for individuals with severe mental illness. Journal of Consulting and Clinical Psychology, 6, 1337-1346.

*Dobson, D. J., McDougall, G., Busheikin, J., \& Aldous, J. (1995). Effects of social skills training and social milieu treatment on symptoms of schizophrenia. Psychiatric Services, 46, 376-380.

Drake, R. E., \& Brunette, M. F. (1998). Complications of severe mental illness related to alcohol and other drug use disorders. In M. Galanter (Ed.), Recent developments in alcoholism: Consequences of alcoholism (Vol. 14, pp. 285-299). New York: Plenum Publishing Company.

*Eckman, T. A., Wirshing, W. C., Marder, S. R., Liberman, R. P., Johnston-Cronk, K., Zimmerman, K., \& Mintz, J. (1992). Technique for training schizophrenic patients in illness self-management: A controlled trial. American Journal of Psychiatry, 149, 1549-1555.

Falloon, I. R., Montero, I., Sungur, M., Mastroeni, A., Malm, U., Economou, E., et al. (2004). Implementation of evidence-based treatment for schizophrenic disorders: Two year outcome of an international field trial of optimal treatment. World Psychiatry, 3, 104-109.

*Finch, B. E., \& Wallace, C. J. (1977). Successful interpersonal skills training with schizophrenic inpatients. Journal of Consulting and Clinical Psychology, 45, 885-890.

Glass, G. V. (1977). Integrating findings: The meta-analysis of research Review Research Education, 5, 351.

Glass, G. V., McGaw, B., \& Smith, M. L. (1981). Meta-analysis in social research. Newbury Park, CA: Sage.

Glynn, S. M., Marder, S. R., Liberman, R. P., Blair, K., Wirshing, W. C., Wirshing, D. A., et al. (2002). Supplementing clinic-based skills training with manual-based community support sessions: Effects on social adjustment of patients with schizophrenia. American Journal of Psychiatry, 159, 829-837.

*Granholm, E., McQuaid, J. R., McClure, F. S., Auslander, L. A., Perivoliotis, D., Pedrelli, P., et al. (2005). A randomized, controlled trial of cognitive behavioral social skills training for middle-aged and older outpatients with chronic schizophrenia. American Journal of Psychiatry, 162, 520-529.

*Gutride, M. E., Goldstein, A. P., \& Hunter, G. F. (1973). The use of modeling and role playing to increase social interaction among asocial psychiatric patients. Journal of Consulting and Clinical Psychology, 40, 408-415.

Hans, S. L., Auerbach, J. G., Asarnow, J. R., Styr, B., \& Marcus, J. (2000). Social adjustment of adolescents at risk for schizophrenia: The Jerusalem Infant Development Study. Journal of the American Academy of Child and Adolescent Psychiatry, 39, 1406-1414.

*Hayes, R. L., Halford, W. K., \& Varghese, F. T. (1995). Social skills training with chronic schizophrenic patients: Effects on negative symptoms and community functioning. Behavior Therapy, 26, 433-449.

Hedges, L. V. (1981). Distribution theory for Glass's estimator of effect 
size and related estimators. Journal of Educational Statistics, 6, 107128.

Hedges, L. V., \& Olkin, I. (1985). Statistical methods for meta-analysis. New York: Academic Press.

*Hogarty, G. E., Anderson, C. M., Reiss, D. J., Kornblith, S. J., Greenwald, D. P., Javna, C. D., \& Madonia, M. J. (1986). Family psychoeducation, social skills training, and maintenance chemotherapy in the aftercare treatment of schizophrenia: I. One-year effects of a controlled study on relapse and expressed emotion. Archives of General Psychiatry, 43, 633-642.

*Hogarty, G. E., Anderson, C. M., Reiss, D. J., Kornblith, S. J., Greenwald, D. P., Ulrich, R. F., \& Carter, M. (1991). Family psychoeducation, social skills training, and maintenance chemotherapy in the aftercare treatment of schizophrenia: II. Two-year effects of a controlled study on relapse and adjustment. Environmental-Personal Indicators in the Course of Schizophrenia (EPICS) research group. Archives of General Psychiatry, 49, 340-347.

Johnson, B. T. (1993). DSTAT: Software for the meta-analytic reviews of research literature (Version. 1.1) [Computer software]. Hillsdale, NJ: Erlbaum.

Kay, S. R., Opler, L. A., \& Fiszbein, A. (1987). The Positive and Negative Syndrome Scale (PANSS) for schizophrenia. Schizophrenia Bulletin, 13, 261-276.

Kopelowicz, A., Liberman, R. P., \& Zarate, R. (2006). Recent advances in social skills training for schizophrenia. Schizophrenia Bulletin, 32(Suppl. 1), S12-S23.

*Kopelowicz, A., Wallace, C. J., \& Zarate, R. (1998). Teaching psychiatric inpatients to re-enter the community: A brief method of improving the continuity of care. Psychiatric Services, 49, 1313-1316.

Kopelowicz, A., Zarate, R., Gonzalez Smith, V., Mintz, J., \& Liberman, R. P. (2003). Disease management in Latinos with schizophrenia: A family-assisted, skills training approach. Schizophrenia Bulletin, 29, 211-227.

Lehman, A. F., \& Steinwachs, D. M. (1998). Patterns of usual care for schizophrenia: Initial results from the Patient Outcomes Research Team (PORT) Client Survey. Schizophrenia Bulletin, 24, 11-20.

Liberman, R. P., Mueser, K. T., Wallace, C. J., Jacobs, H. E., Eckman, T., \& Massel, H. K. (1986). Training skills in the psychiatrically disabled: Learning coping and competence. Schizophrenia Bulletin, 12, 631-647.

*Liberman, R. P., Wallace, C. J., Blackwell, G., Kopelowicz, A., Vaccaro, J. V., \& Mintz, J. (1998). Skills training versus psychosocial occupational therapy for persons with persistent schizophrenia. American Journal of Psychiatry, 155, 1087-1091.

Lipsey, M. W., \& Wilson, D. B. (1993). The efficacy of psychological, educational and behavioral treatment: Confirmation from meta-analysis. American Psychologist, 48, 1181-1209.

Lukoff, D., Wallace, C. J., Liberman, R. P., \& Burke, K. (1986). A holistic program for chronic schizophrenia patients. Schizophrenia Bulletin, 12, 274-282.

*Marder, S. R., Wirshing, W. C., Mintz, J., McKenzie, J., Johnston, K., Eckman, T. A., et al. (1996). Two-year outcome of social skills training and group psychotherapy for outpatients with schizophrenia. American Journal of Psychiatry, 153, 1585-1592.

McGurk, S. R., Twamley, E. W., Sitzer, D. I., McHugo, G. J., \& Mueser, K. T. (2007). A meta-analysis of cognitive remediation in schizophrenia. American Journal of Psychiatry, 164, 1791-1802.

McQuaid, J. R., Granholm, E., McClure, F. S., Roepke, S., Pedrelli, P., Patterson, T. L., \& Jeste, D. V. (2000). Development of an integrated cognitive-behavioral and social skills training intervention for older patients with schizophrenia. The Journal of Psychotherapy Practice and Research, 9, 149-156.

*Meder, J., Morawiec, M., \& Sawicka, M. (1998). Evaluation of the medication management module in Poland. International Review of Psychiatry, 10, 62-66.
*Mueser, K. T., Aalto, S., Becker, D. R., Ogden, J. S., Wolfe, R. S., Schiavo, D., et al. (2005). The effectiveness of skills training for improving outcomes in supported employment. Psychiatric Services, 56, $1254-1260$

Mueser, K. T., \& Bellack, A. S. (1998). Social skills and social functioning. In K. T. Mueser \& N. Tarrier (Eds.), Handbook of social functioning in schizophrenia (pp. 79-96). Needham Heights, MA: Allyn \& Bacon.

Mueser, K. T., Bellack, A. S., Douglas, M. S., \& Morrison, R. L. (1991). Prevalence and stability of social skills deficits in schizophrenia. Schizophrenia Research, 5, 167-176.

Mueser, K. T., Bellack, A. S., Douglas, M. S., \& Wade, J. H. (1991). Prediction of social skill acquisition in schizophrenia and major affective disorder patients from memory and symptomatology. Psychiatry Research, 37, 281-296.

Mueser, K. T., Bellack, A. S., Morrison, R. L., \& Wixted, J. T. (1990). Social competence in schizophrenia: Premorbid adjustment, social skill, and domains of functioning. Journal of Psychiatric Research, 24, 5163

Mueser, K. T., \& Penn, D. L. (2004). Meta-analysis examining the effects of social skills training on schizophrenia. Psychological Medicine, 34, 1365-1367.

National Collaborating Centre for Mental Health. (2003). Schizophrenia: Full national clinical guideline on core interventions in primary and secondary care. London: Gaskell and the British Psychological Society.

National Library of Medicine. (1994). MEDLINE database. McLean, VA: BRS Information Technologies.

Orwin, R. G. (1983). A fail-safe $N$ for effect size in meta-analysis. Journal of Educational Statistics, 8(2), 157-159.

Palmer, B., Heaton, R. K., Kuck, J., \& Braff, D. (1997). Is it possible to be schizophrenic yet neuropsychologically normal? Neuropsychology, 11, 437-446.

Patterson, T. L., Goldman, S., McKibben, C. L., Davidson, K., \& Jeste, D. V. (2001). Social skills performance assessment among older patients with schizophrenia. Schizophrenia Research, 48, 351-360.

*Patterson, T. L., Mausbach, B. T., McKibbin, C., Goldman, S., Bucardo, J., \& Jeste, D. V. (2006). Functional adaptation skills training (FAST): A randomized trial of a psychosocial intervention for middle-aged and older patients with chronic psychotic disorders. Schizophrenia Research, 86, 291-299.

Pfammatter, M., Junghan, U. M., \& Brenner, H. D. (2006). Efficacy of psychological therapy in schizophrenia: Conclusions from metaanalyses. Schizophrenia Bulletin, 32(Suppl. 1), S64-S80.

Pilling, S., Bebbington, P., Kuipers, E., Garety, P., Geddes, J., Martindale, B., et al. (2002). Psychological treatments in schizophrenia: II. Metaanalyses of randomized controlled trials of social skills training and cognitive remediation. Psychological Medicine, 32, 783-791.

Pratt, S. I., Mueser, K. T., Smith, T. E., \& Lu, W. (2005). Self-efficacy and psychosocial functioning in schizophrenia: A mediational analysis. Schizophrenia Research, 78, 187-197.

Pratt, S. I., Van Critters, A. D., Mueser, K. T., \& Bartels, S. J. (in press). Psychosocial rehabilitation in older adults with serious mental illness: A review of the research literature and recommendations for development of rehabilitative approaches. American Journal of Psychiatric Rehabilitation

Rosenthal, R. (1986). Meta-analytic procedures for social research. London: Sage.

Rosenthal, R. (1994). Parametric measures of effect size. In H. Cooper \& L. V. Hedges (Eds.), The handbook of research synthesis (pp. 231-244). New York: Sage.

Sayers, S. L., Curran, P. J., \& Mueser, K. T. (1996). Factor structure and construct validity of the Scale for the Assessment of Negative Symptoms. Psychological Assessment, 8, 269-280. 
*Smith, T. E., Hull, J. W., Romanelli, S., Fertuck, E., \& Weiss, K. A. (1999). Symptoms and neurocognition as rate limiters in skills training for psychotic patients. American Journal of Psychiatry, 156, 1817-1818.

Thorup, A., Peterson, L., Jeppesen, P., Ohlenschlaeger, J., Christensen, T., Krarup, G., et al. (2005). Integrated treatment ameliorates negative symptoms in first episode psychosis: Results from the Danish OPUS trial. Schizophrenia Research, 79, 95-105.

*Tsang, H. W., \& Pearson, V. (2001). Work-related social skills training for people with schizophrenia in Hong Kong. Schizophrenia Bulletin, 27, 139-148.

*Valencia, M., Rascon, M. L., Juarez, F., \& Murow, E. (2007). A psychosocial skills training approach in Mexican out-patients with schizophrenia. Psychological Medicine, 37, 1393-1402.

*Wallace, C. J., \& Liberman, R. P. (1985). Social skills training for patients with schizophrenia: A controlled clinical trial. Psychiatry Research, 15, 239-247.

*Wallace, C. J., \& Tauber, R. (2004). Supplementing supported employment with workplace skills training. Psychiatric Services, 55, 513-515.

*Xiang, Y., Weng, Y., Li, W., Gao, L., Chen, G., Xie, L., et al. (2006). Training patients with schizophrenia with the community re-entry module: A controlled study. Social Psychiatry and Psychiatric Epidemiology, 41, 464-469.

Zubin, J., \& Spring, B. (1977). Vulnerability: A new view of schizophrenia. Journal of Abnormal Psychology, 86, 103-126.

Received July 10, 2007

Revision received November 19, 2007

Accepted November 27, 2007

\section{American Psychological Association SUBSCRIPTION Claims INFORMATION}

Today's Date:

We provide this form to assist members, institutions, and nonmember individuals with any subscription problems. With the appropriate information we can begin a resolution. If you use the services of an agent, please do NOT duplicate claims through them and directly to us. PLEASE PRINT CLEARLY AND IN INK IF POSSIBLE.

PRINT FULL NAME OR KEY NAME OF NSTTTUTION

$\overline{\text { ADDRESS }}$

$\overline{\text { CITY }}$

YOUR NAME AND PHONE NUMBER

TITLE
MEMBER OR CUSTOMER NIMBER (MAY BE FOUND ON ANY PAST ISSUE LABEL)

DATE YOUR ORDER WAS MAILED (OR PHONED)

PREPAID CHECK CHARGE CHECK/CARD CLEARED DATE:

(If possible, send a copy, front and back, of your cancelled check to help us in our research of your claim.

ISSUES: MISSLNG DAMAGED

VOLUME OR YEAR

Thank you. Once a claim is received and resolved, delivery of replacement issues routinely takes 4-6 weeks.

(TO BE FILLED OUT BY APA STAFF)

DATE RECEIVED:

ACTION TAKEN:

STAFF NAME:
DATE OF ACTION:

INV. NO. \& DATE:

LABEL NO. \& DATE:

Send this form to APA Subscription Claims, 750 First Street, NE, Washington, DC 20002-4242

PLEASE DO NOT REMOVE. A PHOTOCOPY MAY BE USED. 